\title{
O gênero Calostoma (Boletales, Agaricomycetidae) em áreas de cerrado e semi-árido no Brasil
}

\author{
Iuri Goulart Baseia ${ }^{1,3}$, Bianca Denise Barbosa Silva ${ }^{1}$, Anileide Gomes Leite ${ }^{1}$ e Leonor Costa Maia ${ }^{2}$
}

Recebido em 3/01/2006. Aceito em 21/09/2006

\begin{abstract}
RESUMO - (O gênero Calostoma (Boletales, Agaricomycetidae) em áreas de cerrado e semi-árido no Brasil). O gênero Calostoma está representado no Brasil por duas espécies: C. cinnabarinum Desv., registrada pela primeira vez no Brasil e C. zanchianus (Rick) Baseia \& Calonge, que ocorrem nas regiões sul, sudeste e nordeste. São fornecidas descrições, ilustrações e imagens em MEV da ornamentação dos esporos.
\end{abstract}

Palavras-chave: Basidiomycota, Gasteromycetes, neotrópicos, Sclerodermataceae, taxonomia

ABSTRACT - (The genus Calostoma (Boletales, Agaricomycetidae) from the Brazilian cerrado and semi-arid areas). The genus Calostoma is represented in Brazil by two species: C. cinnabarinum Desv., reported for the first time in Brazil and C. zanchianus (Rick) Baseia \& Calonge. These species occur in the South, Southeast and Northeast regions. Descriptions, illustrations and SEM-images of spore ornamentation are provided.

Key words: Basidiomycota, Gasteromycetes, Neotropics, Sclerodermataceae, taxonomy

\section{Introdução}

O gênero Calostoma compreende um pequeno grupo do filo Basidiomycota, atualmente inserido na ordem Boletales, com cerca de 15 espécies (Kirk et al. 2001). Por longo período este táxon fez parte de Lycoperdales, ordem dos Gasteromycetes. Os motivos para esta mudança na classificação são as diversas evidências moleculares, com base principalmente no sequienciamento de DNA, que sugerem a origem de Calostoma a partir de um boletóide ancestral, dentre inúmeros outros gêneros anteriormente agrupados em ordens distintas (Hughey et al. 2000; Hibbett \& Binder 2002; Binder \& Bresinsky 2002).

Atualmente existe apenas um registro de Calostoma para o Brasil, feito por Rick (1961) para o Rio Grande do Sul. Nesta obra, póstuma, foi descrita uma espécie nova, Mitremyces zanchianus Rick. Recentemente foi realizada revisão do holótipo, o que resultou em recombinação deste táxon para Calostoma zanchianum, considerando que Mitremyces é sinônimo (Baseia et al. 2006). Diante da escassez de estudos sobre este gênero no Brasil, é objetivo deste trabalho, contribuir para o conhecimento taxonômico do grupo no País.

\section{Material e métodos}

Coletas de gasteromicetos foram realizadas durante o período chuvoso de 1999 , de novembro a março, na Estação Ecológica de Jataí (2133'-2137'S e $48^{\circ} 45^{\prime}-48^{\circ} 51^{\prime} \mathrm{W}$ ) localizada no Estado de São Paulo. Foram realizadas ainda excursões mensais no período chuvoso de 2003, de fevereiro a abril, na Reserva Biológica de Serra Negra ( $8^{\circ} 38^{\prime}-8^{\circ} 35^{\prime}$ 'S e $38^{\circ} 02^{\prime}$ $\left.38^{\circ} 04^{\prime} \mathrm{W}\right)$, Estado de Pernambuco. Essas localidades foram escolhidas como parte de dois projetos mais amplos que visam o levantamento da diversidade de gasteromicetos no bioma cerrado e no semi-árido nordestino.

Os caracteres macroscópicos foram determinados seguindo as técnicas usuais utilizadas em estudos taxonômicos de fungos gasteróides (Pegler et al. 1995). Para Calostoma zanchianum, foi utilizada descrição detalhada do material fresco efetuada pelo coletor, Padre Rômulo Zanchi, que se encontra em anexo com

\footnotetext{
1 Universidade Federal do Rio Grande do Norte, CB, Departamento de Botânica, Ecologia e Zoologia, Laboratório de Micologia, Campus Universitário, Lagoa Nova, 59072-970 Natal, RN, Brasil

2 Universidade Federal de Pernambuco, CCB, Departamento de Micologia, Cidade Universitária, 50670-420 Recife, PE, Brasil

3 Autor para correspondência: baseia@cb.ufrn.br
} 
o holótipo. Os caracteres microscópicos foram determinados de acordo com Miller \& Miller (1988). Esporos foram preparados segundo a técnica de Monthoux (1982) e examinados em microscópio eletrônico de varredura (MEV) modelo Philips XL 20, para observação de detalhes no padrão de ornamentação, a qual é de grande relevância para a taxonomia do grupo aos níveis genérico e específico. Para determinação da coloração foi utilizada a tabela de cores de Kornerup \& Wanscher (1978). Os espécimes estudados foram incorporados ao acervo dos Herbários SP, PACA e UFRN.

\section{Resultados}

Calostoma cinnabarinum Desvaux, J. Bot. 2: 94, 1809.

Fig. 1-3

Basidiomas hipógeos tornando-se epígeos na maturidade, esporóforos subglobosos, estipitados, 1,5-2 cm alt. 0,8-1,2 cm larg. Exoperídio marrom-avermelhado (KW-9E2, reddish brown), 27-30 $\mu$ m espes., superfície lisa, gelatinosa. Endoperídio marrom-avermelhado (KW-8E8, reddish brown), papiráceo, 22-26 $\mu \mathrm{m}$; hifas 2-3 $\mu \mathrm{m}$ diâm. Ostíolo apical, valvar estrelado. Pedicelo estriado, 0,7-1 cm compr., 0,4-0,6 cm larg. Gleba marrom-avermelhada (KW-9F5, reddish brown), pulverulenta; capilícios ausentes, paracapilícios hialinos, 4-6 $\mu \mathrm{m}$ diâm., lisos, asseptados, ramificados, poros ausentes; basidiósporos elípticos, porosos, 12-15×8-10 $\mu \mathrm{m}$ diâm. Ao MEV o epispório apresenta-se com poros bem definidos, apículo ausente.

Hábitat: basidiomas solitários ou em pequenos grupos sobre solo arenoso em áreas de cerrado ou caatinga, rara.

Material estudado: BRASIL. São Paulo: Jataí, Estação Ecológica de Jataí, 24/II/1999, Baseia (SP307573), vegetação de cerrado. Pernambuco: Serra Negra, Reserva Biológica de Serra Negra, 15/VI/2002, Baseia (UFRN-Fungos 192), vegetação de caatinga.

Distribuição: Estados Unidos da América (Burnap 1897; Coker \& Couch 1928), Índia (Boedijn 1938), México (Guzmán 1973; Castro-Mendoza et al. 1983), China (Liu 1984), Costa Rica (Calonge et al. 2005).

Comentários: esta espécie ocorre com maior frequiência no sudeste dos Estados Unidos e México (Castro-Mendoza et al. 1983). Durante os trabalhos de campo, constatou-se que sua ocorrência é muito restrita, sendo coletada em duas ocasiões, sobre solo arenoso, no cerrado e em região de caatinga. Em ambos os casos, as frutificações formaram-se após período de chuvas intensas. Calostoma cinnabarinum caracteriza-se basicamente pelos basidiomas avermelhados, com um esporóforo subgloboso estipitado e ápice com um único ostíolo valvar estrelado (Fig. 1). Todos estes caracteres concordam com os descritos por Massee (1888). Outra característica fundamental para a identificação é a ornamentação dos esporos, com epispório poroso (Fig. 2 e 3). Este constitui o primeiro registro da espécie para o Brasil.

Calostoma zanchianum (Rick) Baseia \& Calonge, Mycotaxon 95: 114, 2006.

Basiônimo: Mitremyces zanchianus Rick in Iheringia Sér. Bot. 9: 456, 1961.

Figs. 4-7

Basidiomas epígeos, esporóforos ovóides, estipitados, 2,6 cm alt. $1 \mathrm{~cm}$ larg. Exoperídio branco amarelado (KW-3A2, yellowish white), 45 um espes., superfície rugosa, gelatinosa. Endoperídio rosa claro (KW-8A2, pinkish white), cartilaginoso, 22-26 $\mu \mathrm{m}$; hifas $3 \mu \mathrm{m}$ diâm. Ostíolo apical, valvar estrelado, consistindo de 4 fendas muito longas $(1 \mathrm{~cm})$. Pedicelo dilatado, subgloboso, 1,2 cm compr., 1,3 cm larg. Gleba marromavermelhada (KW-9F4, reddish brown), mucilaginosa; Capilícios e paracapilícios ausentes; basidiósporos fusiformes a elípticos, lisos, hialinos a amarelados, apresentando um longo sulco longitudinal, apículo ausente.

Hábitat: basidioma solitário.

Material estudado: BRASIL. Rio Grande do Sul: Cachoeira do Sul, III/1943, Zanchi (PACA 19.673, Holotipo).

Distribuição: Brasil (Rick 1961).

Comentários: Calostoma zanchianum é fundamentalmente caracterizada por apresentar: pedicelo fortemente dilatado e boca consistindo de quatro longas fendas (Fig. 4); esporos elípticos a fusiformes com uma fenda longitudinal (Fig. 5-6). Estes caracteres separam Calostoma zanchianum das demais espécies do gênero. Esta espécie foi coletada numa única ocasião, pelo Padre Rômulo Zanchi em 1943 que a enviou para Johannes Rick. Na realidade, Rick não chegou a publicar a descrição desta espécie, que é referida numa série póstuma denominada Basidiomycetes Eubasidii in Rio Grande do Sul - Brasilia, graças ao esforço do Padre Balduíno Rambo, que copilou todas as espécies estudadas e coletadas por Rick, incluindo diversos táxons ainda não publicados. Desta forma, a descrição 


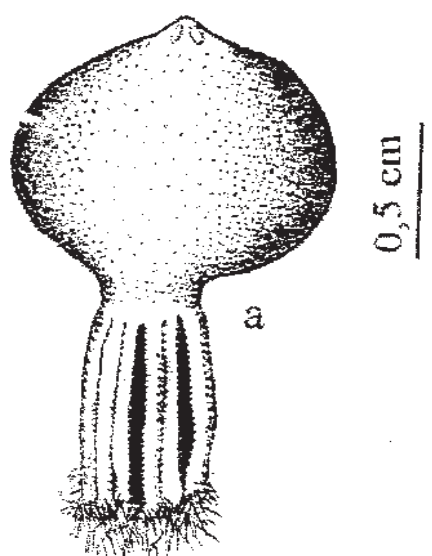

Figura 1. Calostoma cinnabarina: a. basidioma; b. superfície apical.
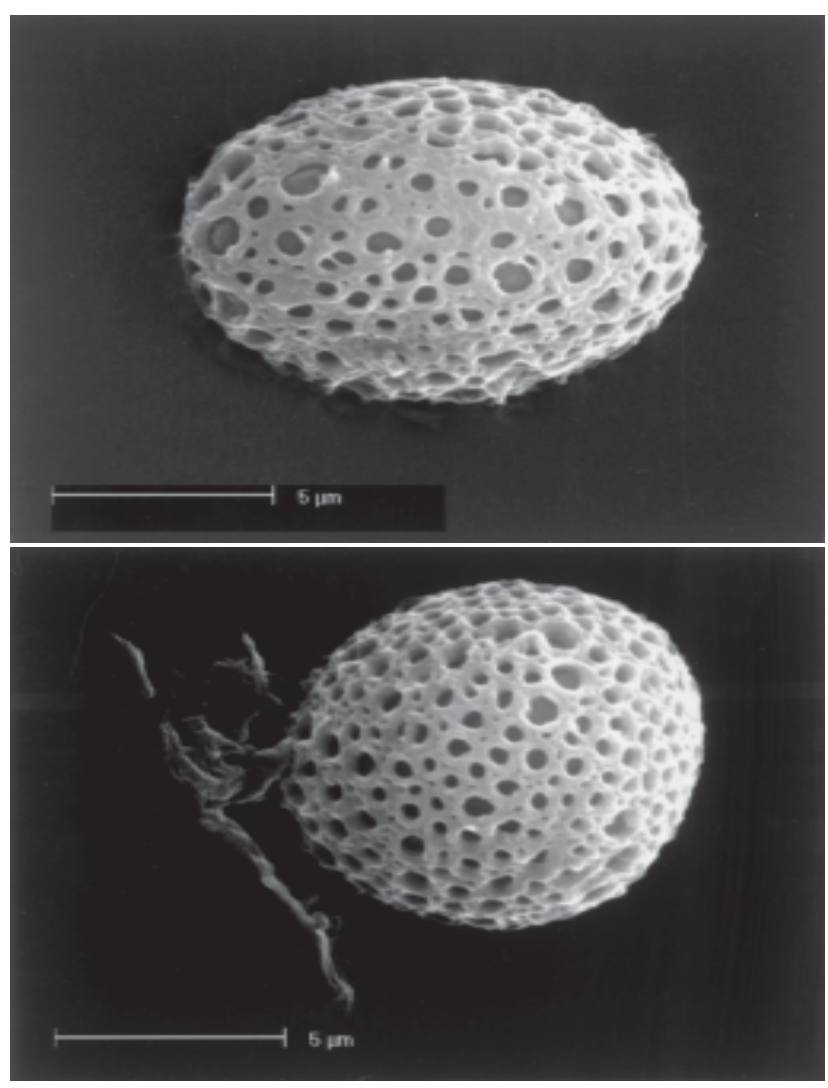

Figuras 2-3. Calostoma cinnabarina: basidiósporos em MEV.

de Mitremyces zanchianus foi publicada 15 anos após a morte de Rick em 1946. Infelizmente, o único material conhecido desta espécie é o holótipo.

\section{Agradecimentos}

Os autores agradecem ao Curador do Herbário Anchieta (PACA), pelo empréstimo do holótipo; ao
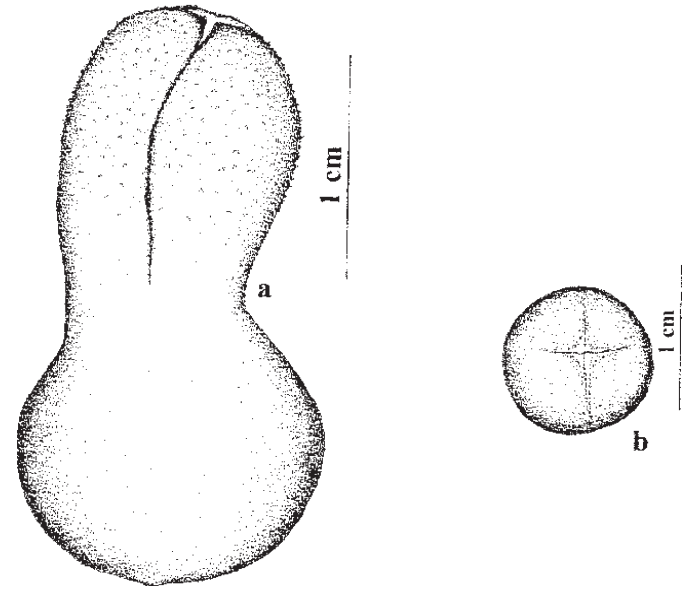

Figura 4. Calostoma zanchianum: a. basidioma; b. superfície apical.
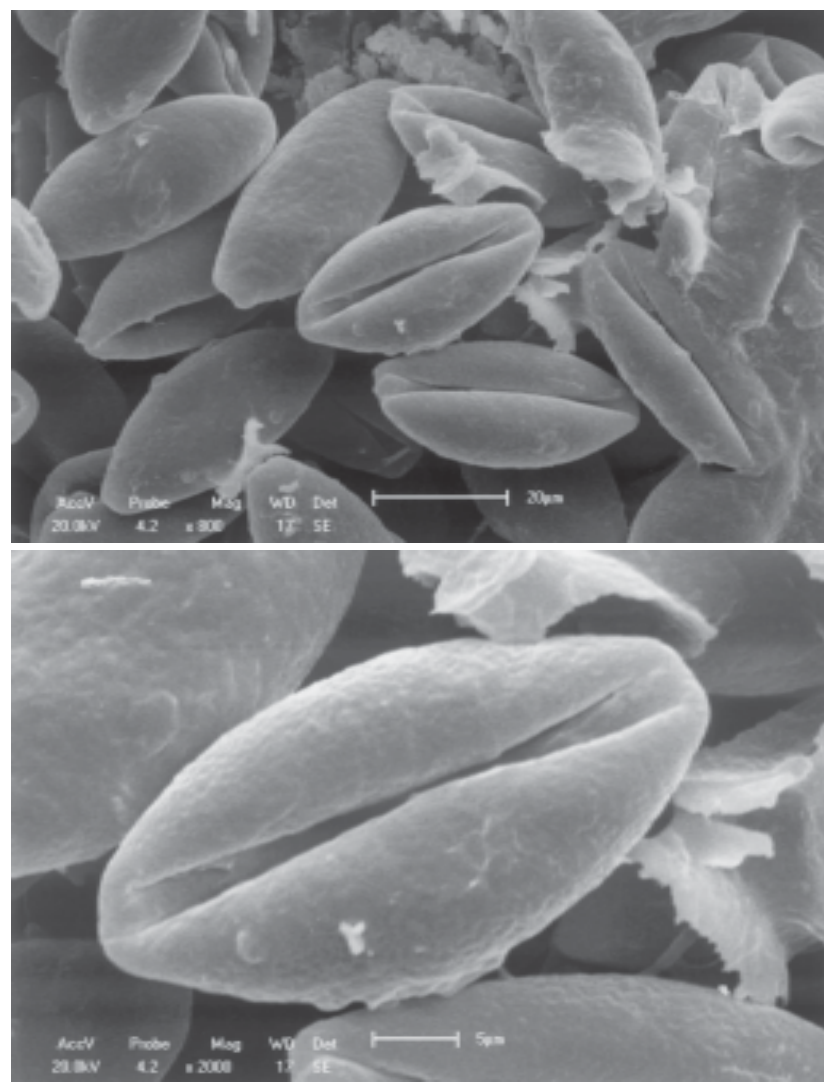

Figuras 5-6. Calostoma zanchianum: basidiósporos em MEV.

Prof. Francisco Diego Calonge (Real Jardim Botânico de Madrid, Espanha), pela confirmação na identificação das espécies; a Tereza Cristina de Oliveira Galvão pelas ilustrações; ao Conselho Nacional de Desenvolvimento Científico e Tecnológico (CNPq), pelo suporte financeiro; ao Departamento de Micologia da Universidade Federal de Pernambuco, pelo suporte físico. 


\section{Referências bibliográficas}

Baseia, I.G.; Cortez, V.G. \& Calonge, F. D. 2006. Rick’s species revision: Mitremyces zanchianus versus Calostoma zanchianum. Mycotaxon 95: 113-116.

Binder, M. \& Bresinsky, A. 2002. Derivation of a polymorphic lineage of Gasteromycetes from boletoid ancestors. Mycologia 94(1): 85-98.

Burnap, C.E. 1897. Contributions from the cryptogamic laboratory of Harvard University. Notes on the genus Calostoma. Botanical Gazette 23: 180-196.

Boedijn, K.B. 1938. The genus Calostoma in the Netherlands Indies (Fung. Bas.). Bulletin du Jardin Botanique de Buitenzorg 16(3): 64-75.

Calonge, F.D.; Mata, M. \& Carranza, J. 2005. Contribución al catálogo de los Gasteromycetes (Basidiomycotina, Fungi) de Costa Rica. Anales del Jardín Botánico de Madrid 62(1): 23-45.

Castro-Mendoza, E.; Miller, O.K. \& Stetler, D.A. 1983. Basidiospore wall ultraestructure in the genus Calostoma in North America. Mycologia 75(1): 36-45.

Coker, W.C. \& Couch, J.N. 1928. The Gasteromycetes of Eastern United States and Canada. Baltimore, Waverly Press.

Guzmán, G. 1973. Observaciones sobre el gênero Calostoma en México. Boletin de la Sociedad Mexicana de Micologia 7: 99-116.
Hibbett, D.S. \& Binder, M. 2002. Evolution of complex fruiting-body morphologies in homobasidiomycetes. Biological Sciences 269(1504): 1963-1969.

Hughey, B.D.; Adams, G.C.; Bruns, T.D. \& Hibbett, D.S. 2000. Phylogeny of Calostoma, the gelatinous-stalked puffball, based on nuclear and mitochondrial ribosomal DNA sequences. Mycologia 92(1): 94-104.

Kirk, P.M.; Cannon, P.F.; David, J.C. \& Stalpers, J.A. 2001. Ainsworth \& Bisby's Dictionary of the Fungi. Ninth Edition, CAB International, UK (http:// biodiversity.uno.edu/ fungi/).

Kornerup, A. \& Wanscher, J. E. 1978. Methuen Handbook of Colour, Third Edition, London Methuen, UK.

Liu, B. 1984. The Gasteromycetes of China. Beihefte zur Nova Hedwigia 74: 1-235.

Massee, G. 1888. A monograph of the genus Calostoma Desv. (Mitremyces Nees). Annales of Botany 2: 25-46.

Miller, O.K. Jr. \& Miller, H.H. 1988. Gasteromycetes: Morphology and Developmental Features. Mad River, Eureka, CA.

Monthoux, O. 1982. Micromorphologie des spores et capillitiums des Gastéromycètes des stations xériques de la region de Genève, etudiée au microscope électronique à balayage (SEM). Candollea 37(1): 63-99.

Pegler, D.N.; Laessøe, T. \& Spooner, B.M. 1995. British puffballs, earthstars and stinkhorns, An account of the British gasteroid fungi. Kew, Royal Botanic Gardens.

Rick, J. 1961. Basidiomycetes Eubasidii no Rio Grande do Sul. Brasília. Iheringia 9: 451-480. 